Research Article

\title{
Dynamic Large Deflection Response of RC Beams under Low-Speed Impact Loading
}

\author{
Lu Guo, ${ }^{1,2}$ Renwei Mao, ${ }^{3}$ Zhifang Liu $\mathbb{D}^{1,2}$ Shiqiang Li, ${ }^{1,2,4}$ Guiying Wu $\mathbb{D}^{1,2}$ \\ and Zhihua Wang $\mathbb{D}^{1,2}$ \\ ${ }^{1}$ Institute of Applied Mechanics, College of Mechanical and Vehicle Engineering, Taiyuan University of Technology, \\ Taiyuan 030024, Shanxi, China \\ ${ }^{2}$ Shanxi Key Laboratory of Material Strength and Strength Impact, College of Mechanical and Vehicle Engineering, \\ Taiyuan University of Technology, Taiyuan 030024, Shanxi, China \\ ${ }^{3}$ Department of Engineering Mechanics, Zhejiang University, Hangzhou 310012, Zhejiang, China \\ ${ }^{4}$ State Key Laboratory of Advanced Design and Manufacturing for Vehicle Body, Changsha 410082, Hunan, China
}

Correspondence should be addressed to Zhifang Liu; liuzhifang@tyut.edu.cn, Guiying Wu; wgy2005112@163.com, and Zhihua Wang; wangzh077@163.com

Received 18 May 2020; Revised 22 August 2020; Accepted 29 August 2020; Published 22 October 2020

Academic Editor: Hamid Toopchi-Nezhad

Copyright $\odot 2020 \mathrm{Lu}$ Guo et al. This is an open access article distributed under the Creative Commons Attribution License, which permits unrestricted use, distribution, and reproduction in any medium, provided the original work is properly cited.

\begin{abstract}
The dynamic large deflection response of RC beams under low-speed impact loading at their midspan is investigated in this paper. Two simple methods such as extended Hamilton's principle and equivalent static hypothesis are used to establish the theoretical models for both simply supported and fully clamped RC beams; analytical formulas for the maximum midspan deflection-input impact energy are obtained. The "equal area" method based on the deflection history of beams is only used during these derivations to determine the plastic bending moment and the stress distribution of the structure. Then, finite element simulations are carried out to verify the validity of the proposed predictions. It is shown that the maximum deflections for both simply supported and fully clamped beams are almost proportional with respect to the input impact energy, which agrees well with both simulations and other experimental results. Also, the boundary condition has more effect on the deflection response of the RC beams which is relatively longer.
\end{abstract}

\section{Introduction}

Reinforced concrete (RC) structures are common composite constructs, constituting plain concrete and steel reinforcement, which have been widely used in buildings and other infrastructures. In addition to static loading condition, RC structures are often subjected to impact loadings such as air blasts, falling heavy loadings and earthquakes. The assessment for the dynamic response of these structures under such loadings is very important.

To provide the design guide for RC structures, equivalent static hypothesis has been commonly used in many codes. For example, a guide had been provided by BSI [1] to determine an equivalent static force on the structures such as ships or vehicles that were impacted. An empirical equation has been proposed by AASHTO [2] to predict the equivalent static impact force for the vessel with the given impact velocity and deadweight tonnage of the structures, where dynamic analysis is not required for both design codes mentioned above. More recently, dynamic analysis has been carried out to investigate the effect of the inertia force distribution on the bending moment and shear force for RC beams subjected to high-rate impact loading [3]. However, not much attention has been paid to predict the maximum or residual deflection of the RC beams under a given input energy, which is deemed to play a part for the assessment of the load-carrying capacity of RC beams.

A large number of experiments have been conducted to establish an impact-resistant design method for RC structures [4-10], among which an empirical formula has been proposed by Kishi et al. [4] depending on the static flexural load-carrying capacity, input impact energy, and the 
maximum deflection/or residual deflection. A series of lowspeed impact experiments were performed by Tachibana et al. [7] to collect fundamental data and establish a performance-based design method for RC beams. Then, lowspeed falling weight impact tests on a total of 36 beams with different section parameters have been conducted by Kishi and Hiroshi Mikami [8], and two empirical equations have been derived based on the test results. In parallel studies, a new empirical model has been proposed by Pham and Hao [11] to predict the maximum impact force on RC beams subjected to drop weight impact by artificial neural network (ANN), and the model has been verified against a database including 67 RC beams. Besides, a series of tests have been conducted by Tingbian Zhan et al. [10]. They have designed simply supported RC beams with symmetry three-layer arrangement of reinforcements and proposed a hypothesis that the residual/or maximum deflections of these beams are linearly proportional to the input impact energy. However, theoretical model on the midspan deflection-input impact energy relationship of RC beams is still limited.

Furthermore, the development of the numerical analysis method for simulating these dynamic responses of the RC structures is ongoing [12-20]. Rabczuk and Belytschko $[19,20]$ proposed a new approach for modelling discrete cracks in meshfree methods for both $2 \mathrm{D}$ and 3D problems; the results show good coherence with experimental data, including highly dynamic events with extremely large deformations and strain-rate effects. Meanwhile, it has been shown that, for relatively low loading rate, the failure of the $\mathrm{RC}$ beams is due to bending, and with the increase in loading rate, there is a transition of the failure mode from bending to shear [18]. For the concrete damaged plasticity (CDP) model which is implemented in Abaqus software, some important aspects and the determination of proper values for some parameters had been investigated by Szczecina and Winnicki [21], and they discussed the relaxation time parameter in the CDP model [22], and both of these investigations have been checked.

More recently, studying on the high-performance strengthening concrete structures has become a hotspot [11, 23-27]. Similar to the traditional concrete structure, many investigations about the dynamic behavior of these structures subjected to impact loading have been carried out. The impact resistance of structures strengthened with FRP, including RC beams, RC slabs, RC columns, and masonry walls had been summarized [11].

Note that theoretical studies on the midspan deflectioninput impact energy relationship of RC beams are still inadequate. Besides, the behavior of the RC structures under impact loading is not only about the input impact energy but also about the size or mass of the impactor and the impact velocity; it differs with a large mass impact but low velocity or small mass but high velocity although the kinetic energy is the same. So, investigation about the dynamic response of RC structures under both low- and high-speed impact loading is necessary. As studies on the deflection response of the RC beams subjected to low-speed impact loading are relatively limited, in the present paper, the dynamic large deflection response of RC beams under low-speed impact loading is investigated theoretically and numerically. Extended Hamilton's principle and upper bound method are used to establish the theoretical models in Section 2. In these derivations, "equal area" hypothesis is used to estimate the plastic bending moment for beams with large deflection. Then, finite element simulations for both simply supported and fully clamped beams are outlined in Section 3. The comparison between Kishi's experimental results, theoretical predictions, and simulation results is discussed in Section 4. In the end, the conclusions of this paper are summarized.

\section{Analysis of RC Beams under Low-Speed Impact Loading}

2.1. Extended Hamilton's Principle. For a nonconservative system, extended Hamilton's principle has been proposed to describe the motion of the system as [28]

$$
\begin{aligned}
\delta J & =\delta \int_{t_{0}}^{t_{1}}(T-U) \mathrm{d} t \\
& =\int_{t_{0}}^{t_{1}} \delta E \mathrm{~d} t,
\end{aligned}
$$

where $T$ stands for the kinetic energy, $U$ stands for the potential energy, and $\delta E$ stands for the dissipated energy during time $\mathrm{d} t$.

2.1.1. Simply Supported RC Beams. Consider a case of a simply supported reinforcement concrete beam with an overhang $H$ beyond the outer rollers. As shown in Figure 1, the weight $N_{0}$ is vertically dropped with initial velocity $V_{0}$ at the midspan of the beam. The basic assumptions of this theoretical model are as follows:

(1) The materials are rigid perfectly plastic [28].

(2) Half of the structure is taken due to symmetry. The first segment is considered between the midspan and the support of the beam, and the other is the hangout segment. Both these undergo rigid motion, as shown in Figure 1.

(3) Velocity field of the first and hangout segment is $\dot{w}_{1}=\left(1-x_{1} / l\right) \dot{w}_{0}$ and $\dot{w}_{2}=-\dot{w}_{0} x_{2} / l$, respectively.

(4) The RC beams are assumed as "under-reinforced" so that, in pure bending, yielding of steels contributes more to the plastic deformation of the beams rather than crushing of the concrete.

$l$ is the half span of the RC beam and $w_{0}$ represents the deflection for the midspan of the beams.

The modified formula is used in the structure as follows:

$$
\begin{aligned}
\delta J= & \delta\left[\int_{0}^{t_{f}} \frac{1}{2} N_{0} \dot{w}_{0}^{2} \mathrm{~d} t+\int_{0}^{t_{f}} \int_{0}^{l} 2 \cdot \frac{1}{2} m \dot{w}_{1}^{2} \mathrm{~d} x \mathrm{~d} t\right. \\
& \left.+\int_{0}^{t_{f}} \int_{0}^{H} 2 \cdot \frac{1}{2} m \dot{w}_{2}^{2} \mathrm{~d} x \mathrm{~d} t\right]=\int_{0}^{t_{f}} 2 M_{0 s} \delta \theta \mathrm{d} t
\end{aligned}
$$

in which $m$ is the linear density of the RC beams, $t_{f}$ is the symbol for duration of the response, and $M_{0 s}$ represents the 


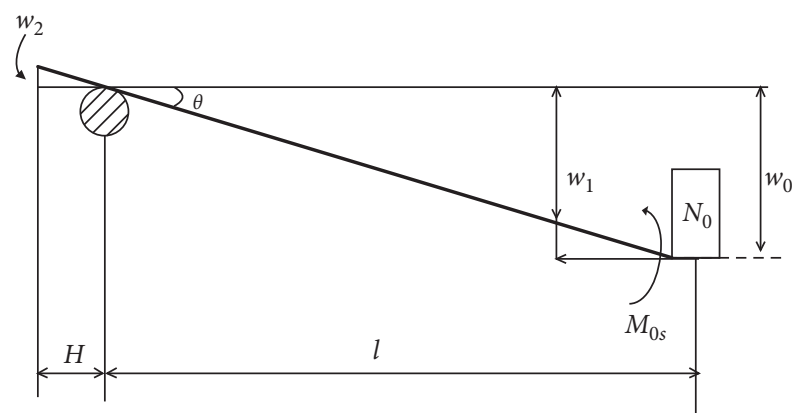

FIGURE 1: Displacement field of a simply supported RC beam with a heavy striker at its midspan.

bending moment in the plastic hinge. The deflection for the midspan of the beam can be assumed as

$$
w_{0}(t)=\frac{C_{1}}{2}\left(t-t_{f}\right)^{2}+C_{2}
$$

together with the initial and final condition: $w_{0}(0)=0$, $\dot{w}_{0}(0)=V_{b}$, and $\dot{w}_{0}\left(t_{f}\right)=0 ; V_{b}$ is taken as the residual velocity of the striker and also the initial velocity for the midspan of the beam after instantaneous impacting. Then, the maximum deflection $w_{0 f}$ can be obtained as follows:

$$
\begin{aligned}
w_{0 f} & =\frac{V_{b}^{2} l\left(N_{0}+(2 / 3) m l+\left(2 H^{3} / 3 l^{2}\right) m\right)}{4 M_{0 s}} \\
& =\frac{(1 / 2) N_{0} V_{b}^{2} l\left(1+\left(2 m l / 3 N_{0}\right)+\left(2 H^{3} / 3 l^{2}\right)\left(m / N_{0}\right)\right)}{2 M_{0 s}} .
\end{aligned}
$$

Since momentum is conserved during the instantaneous impact process, the governing equation for the system can be provided as

$$
N_{0} V_{0}=N_{0} V_{b}+m l V_{b}-m \frac{H^{2}}{l} V_{b},
$$

where $V_{0}$ is the initial impact velocity of the striker.

Hence, (3) can be rewritten as

$$
w_{0 f}=\frac{E_{k} l\left(1+\left(2 m l / 3 N_{0}\right)+\left(2 H^{3} / 3 l^{2}\right)\left(m / N_{0}\right)\right)}{2 M_{0 s}\left[1+\left(m / N_{0}\right)\left(l-\left(H^{2} / l\right)\right)\right]^{2}},
$$

where $E_{k}$ is the input impact energy, and this equation shows the linear relationship between the input energy and the maximum deflection of the beam. The duration $t_{f}$ is obtained as

$$
t_{f}=\frac{V_{0} l\left(1+\left(2 m l / 3 N_{0}\right)+\left(H^{3} m / 3 l^{2} N_{0}\right)\right)}{\left(2 M_{0 s} / N_{0}\right)\left(1+\left(m l / N_{0}\right)-\left(m H^{2} / N_{0} l\right)\right)} .
$$

Note that $M_{0 s}$ in (6) and (7) is the only unknown quantity, which can then be given by the "equal area" method. The "equal area" method is supposed to analyse the large deflection response of the structures, which turns out to be incomparably simpler than the conventional way [29].
This method is extended to determine the plastic bending moment and stress distribution of the RC beams in this paper. It is assumed that, during the deflection process, a random transverse cross section of each half RC beam rotates about an instantaneous centre $I$ as a rigid body, as sketched in Figure 2. Besides, the position of $I$ equates the "area" above and below it during the deformation history. This method is carried out based on the force equilibrium and the upper bound calculation.

For simply supported cases, the force equilibrium is given by equating the tensile force in the steel and the compressive force in the concrete:

$$
f_{c} \mu d=\sigma_{y} r d
$$

where $f_{c}$ is the cube crushing strength of the concrete, $\sigma_{y}$ is the yield strength of the steel, $r$ represents the reinforcement ratio of the structure, $\mu d$ is the depth of the compression zone, and $d$ is the depth of the cross section. It is obvious that the simply supported ends are unable to provide the horizontal reaction for RC beams, and forces for the RC beams are supposed to keep a balance during the deformation. So, I is always located at the bottom of the equivalent compression zone of the beam, see Figure 2. So, $M_{0 s}$ is taken as a constant value:

$$
M_{0 s}=\frac{1}{2} f_{c} b \mu^{2} d^{2}+\sigma_{y} r d b(d-\mu d)
$$

Furthermore, the equation of $M_{0 s}$ can be extended for double "under-reinforced" beams, whose reinforcements in the compressive zone have relative negligible effect on the load-carrying capacity of the beam.

2.1.2. Fully Clamped RC Beams. The deformation process of the fully clamped RC beams is considered as the beam deforms with four plastic hinges. two adjacent to the striker and others lie in the boundary, as illustrated in Figure 3.

For fully clamped condition,

$$
\begin{aligned}
\delta J & =\delta\left[\int_{0}^{t_{f}} \frac{1}{2} N_{0} \dot{w}_{0}^{2} \mathrm{~d} t+\int_{0}^{t_{f}} \int_{0}^{l} 2 \cdot \frac{1}{2} m \dot{w}_{1}^{2} \mathrm{~d} x \mathrm{~d} t\right] \\
& =\int_{0}^{t_{f}} 4 M_{0 f} \delta \theta \mathrm{d} t,
\end{aligned}
$$

where $M_{0 f}$ is taken as a constant value as presented in (9). Substituting the same deflection equation and initial and final conditions as in the simply supported one into (10), there is

$$
\begin{aligned}
w_{0 f} & =\frac{V_{b}^{2} l\left(N_{0}+(2 / 3) m l\right)}{8 M_{0 f}} \\
& =\frac{(1 / 2) N_{0} V_{b}^{2} l\left(1+\left(2 m l / 3 N_{0}\right)\right)}{4 M_{0 f}} .
\end{aligned}
$$

As the system satisfies the governing equation,

$$
N_{0} V_{0}=N_{0} V_{b}+m l V_{b} \text {. }
$$




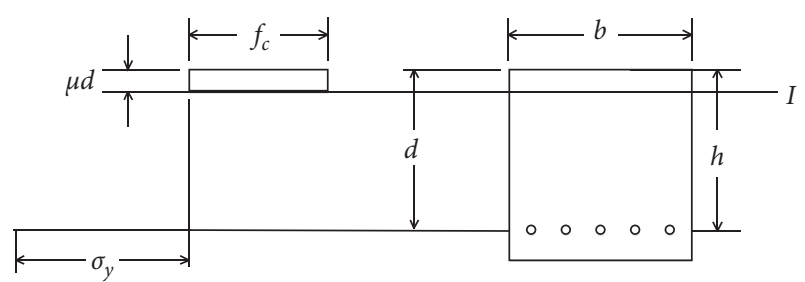

Figure 2: Area diagrams for simply supported RC beams.

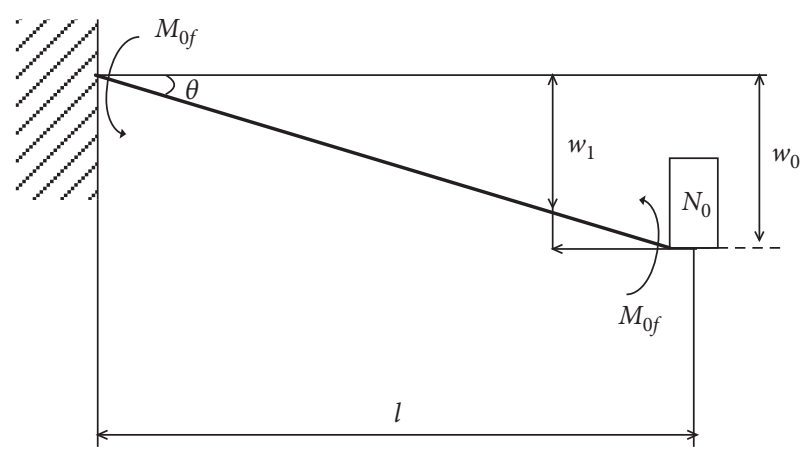

FIgURE 3: Displacement field of a fully clamped RC beam with a heavy striker at its midspan.

Then, (11) becomes

$$
w_{0 f}=\frac{E_{k} l\left(1+\left(2 m l / 3 N_{0}\right)\right)}{4 M_{0 f}\left[1+\left(m l / N_{0}\right)\right]^{2}}
$$

The above equation presents the linear maximum midspan deflection-input impact energy relationship of RC beams under fully clamped condition theoretically. Meanwhile, the duration $t_{f}$ is

$$
t_{f}=\frac{V_{0} l\left(1+\left(2 m l / 3 N_{0}\right)\right)}{\left(4 M_{0} / N_{0}\right)\left(1+\left(m l / N_{0}\right)\right)} \text {. }
$$

2.2. Equivalent Static Hypothesis. The large deflection response for both simply supported and clamped RC beams under low-velocity impact is investigated by another comparably simpler method in this section. Equivalent static hypothesis is adopted, and the energy and momentum governing equations are used to establish the prediction equations for the maximum deflection of the beam. For fully clamped condition, the variable bending moment of the beam with different deformation phases is taken into account and is calculated by the "equal area" method.

For simplicity, both assumptions (1) and (4) are introduced same as the previous section.

2.2.1. Simply Supported RC Beams. With the same displacement field shown in Figure 1, equivalent static hypothesis makes it possible to use the governing equation for structures given by

$$
\frac{1}{2} N_{0} V_{b}^{2}+\frac{1}{3} m l V_{b}^{2}+\frac{1}{3} m \frac{H^{3}}{l^{2}} V_{b}^{2}=2 M_{1 s} \theta,
$$

where $\theta=w_{0 f} / l$ and $M_{1 s}$ represents the bending moment in the plastic hinge which equals to $M_{0 s}$, which has been determined by the "equal area" method shown in (5); the maximum deflection $w_{0 f}$ can be derived from the aforementioned equation as

$$
w_{0 f}=\frac{V_{b}^{2} l\left(N_{0}+(2 / 3) m l+\left(2 H^{3} / 3 l^{2}\right) m\right)}{4 M_{1 s}} .
$$

Thus, both methods can obtain the same prediction for the maximum deflection-input energy relationship for beams under simply supported condition as follows:

$$
w_{0 f}=\frac{E_{k} l\left(1+\left(2 m l / 3 N_{0}\right)+\left(2 H^{3} / 3 l^{2}\right)\left(m / N_{0}\right)\right)}{\left[f_{c} b \mu^{2} d^{2}+2 \sigma_{y} r d b(d-\mu d)\right]\left[1+\left(m / N_{0}\right)\left(l-\left(H^{2} / l\right)\right)\right]^{2}} .
$$

2.2.2. Fully Clamped RC Beams. Consider the displacement field of fully clamped RC beams as indicated in Figure 3; four plastic hinges are formed during the deformation process. > The upper bound theorem for the system can be given as:

$$
\frac{1}{2} N_{0} V_{b}^{2}+\frac{1}{3} m l V_{b}^{2}=4 \int_{0}^{w_{0 f}} M_{1} \mathrm{~d} \theta
$$

in which $\theta=\Delta / l$. $\Delta$ represents the deflection for the midspan of the beam.

To calculate the plastic bending moment $M_{1}$ in the above equation, the same method as in the previous section is used.. So $I$ should have a distance $\mu d$ below the upper flanges to satisfy (8). Taking the fact that fully clamped ends can provide transverse reaction loading, two phases are divided during the deformation as shown in Figure 4.

(1) When the deflection $\Delta \leq 2 \mu d$ :

$$
M_{11}=\frac{1}{8} \alpha f_{c} b(2 \mu d-\Delta)^{2}+\sigma_{y} r d b(d-\mu d+(\Delta / 2))
$$

(2) When the deflection $\Delta \geq 2 \mu d$ :

$$
M_{12}=\sigma_{y} r d(d-2 \mu d+\Delta) .
$$

Substitute (19) and (20) into (18), and the maximum deflection $w_{0 f}$ can be determined by solving the simple monobasic quadratic or cubic equations.

(1) For $w_{0 f} \leq 2 \mu d$,

$$
w_{0 f}=\left[-\frac{q}{2}+\left(\frac{q^{2}}{4}+\frac{p^{3}}{27}\right)^{(1 / 2)}\right]^{(1 / 3)}+\left[-\frac{q}{2}-\left(\frac{q^{2}}{4}+\frac{p^{3}}{27}\right)^{(1 / 2)}\right]^{(1 / 3)},
$$

$$
\text { where } \quad p=24\left(\left(\sigma_{y} r d^{2}-(1 / 2) \sigma_{y} r \mu d^{2}\right) / f_{c}\right) \text { and }
$$
$q=-\left[E_{k} 6 l\left(1+\left(m l / 3 N_{0}\right)\right)\right] /\left[f_{c} b\left(1+\left(m l / N_{0}\right)\right)^{2}\right]$.

(2) For $w_{0 f} \geq 2 \mu d$, 


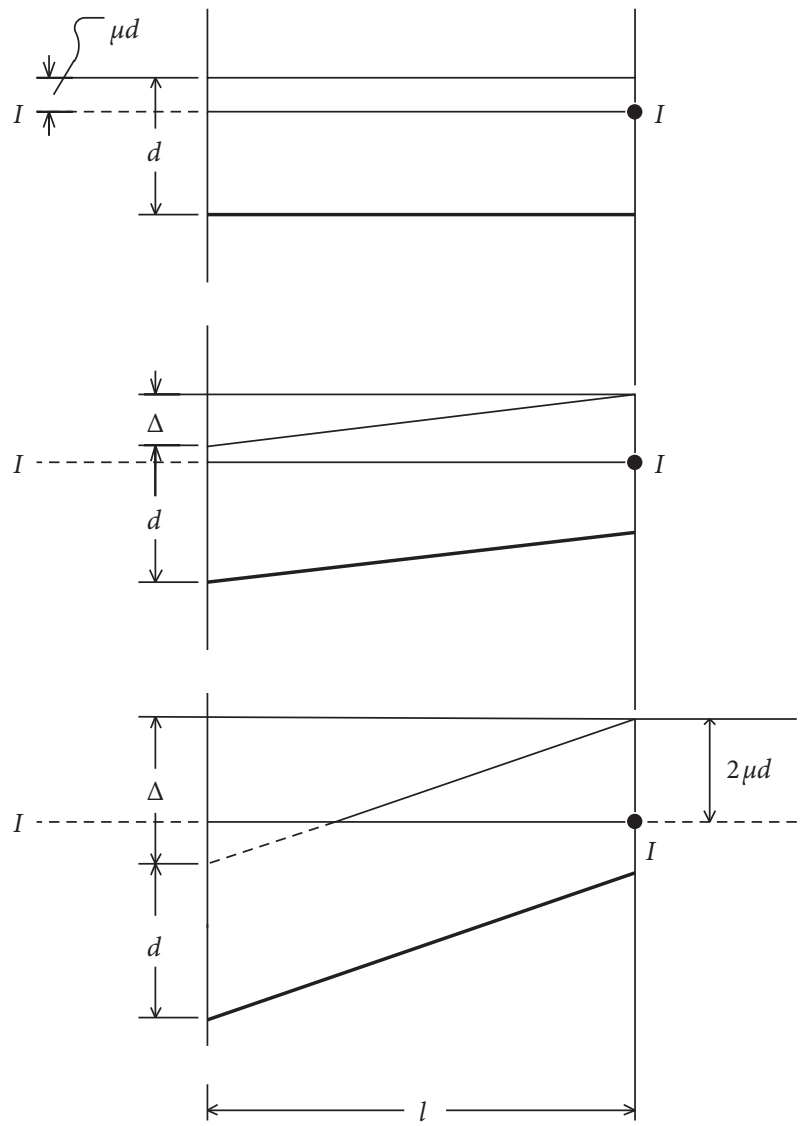

FIgUre 4: Area diagrams for fully clamped RC beams.

$$
w_{0 f}=\frac{-c+\left(c^{2}-4 a e\right)^{(1 / 2)}}{2 a},
$$

where $a=(2 / l) \sigma_{y} r d b, \quad c=(4 / l) \sigma_{y} r d b(d-\mu d)$, and $e=$ $(16 / 3 l) \sigma_{y} r \mu^{2} d^{3} b-E_{k}\left(\left(1+m l / 3 N_{0}\right) /\left(1+m l / N_{0}\right)^{2}\right)$. Thus, (21) and (22) describe the nonlinear maximum deflectioninput energy relationship for the fully clamped RC beam.

\section{Finite Element Analysis}

3.1. FE Model. To verify the validity of the proposed analysis, numerical models are developed in Abaqus to simulate the experimental low-speed impact tests reported by Kishi [8] and Adhikary et al. [30].The model and the parameters of the RC beams are shown in Figure 5 and Table 1, respectively. And all of the specimens have the same overhang $200 \mathrm{~mm}$. The explicit integration solution technique is adopted in this analysis. In simulation, load is applied through the kinetic energy of dropping mass.

For concrete, eight-node three-dimensional element C3D8R is used to discretize the concrete [31]. As for reinforcements, two-node three-dimensional truss element T3D2 is employed to model the reinforcements. And the steel is embedded into the concrete, where the bond and drawing force between the concrete and steel are neglected. The mesh convergence test is conducted prior the numerical study. Structure with different mesh types or sizes has been employed to study mesh sensitivity, and simulation results are presented in Figure 6, in which the relative error on the peak impact force and the maximum midspan deflection for the RC structure with mesh sizes $10 \mathrm{~mm}$ and $5 \mathrm{~mm}$ are less than 5\%. Therefore, structured element C3D8R and a mesh size of $10 \mathrm{~mm}$ were used to create the solid elements which seemed to be ideal as the unstructured element and further decrease in mesh size almost generated the same results however augmented the computational time. Furthermore, different step time increment is also considered to investigate the influence of the time increment on the simulation results, and changing of the increment presents no effect on the response of the RC beams under low-speed impact in these simulations, as shown in Figure 6(c).

Both simply supported and fully clamped RC cases are studied in this investigation. It has been studied that the model of the boundary is significant for the reliability of numerical results. To make sure of the consistency between the simulation and experimental test, the actual structure is modeled in simply supported cases [8], where the supports, steel plates, and load cells are included, as shown in Figure 5. Meanwhile, models have also been modeled to replicate the same experimental conditions conducted by Adhikary et al. [30], as shown in Figure 5(b). Both of them are constrained as rigid bodies, and their density is $7800 \mathrm{~kg} / \mathrm{m}^{3}$, elastic modulus is $200 \mathrm{Gpa}$, and yield strength is $500 \mathrm{Mpa}$, respectively. For fully clamped condition, the displacement for end nodes in any direction is constrained to vanish.

According to the conservation of energy, the kinetic energy of the impactor before impact should be equal to the sum of the current kinetic energy, the internal energy of the beam, and the energy loss due to friction and hourglass modes during a simulation. The variation of various energies in a typical impact simulation is shown in Figure 7, where the energy loss due to friction is very small and can be neglected. And the hourglass energy is around $2.22 \%$ of the total energy at the peak impact load and around $7.35 \%$ of the total energy at the maximum midspan deflection, which satisfy the rule of thumb $(<10 \%)$ [30].

3.2. Material Model. Concrete is assumed as the concrete damage plasticity (CDP) model. This model is one of the most common constitutive models for RC structures implemented in ABAQUS software and has been investigated by previous studies [21, 22]. Its theoretical mode has been proposed by Lubliner et al. [32], in which the main failure mechanisms for concrete materials are cracking in tension and crushing in compression [33]. Stress and strain characteristics for the CDP model are shown in Figure 8. On the compression side, the material is assumed as linear elastic without initial damage before $\sigma_{c 0}$ (the initial compressive yield strength), and the strengthening stage is followed between $\sigma_{c 0}$ and $\sigma_{\text {cu }}$ (the ultimate stress). Then, the stiffness degradation as $\left(1-d_{c}\right) E_{0}$ in the softening stage in which $d_{c}$ is the damage factor for compression side. And this relationship between stress-strain can be expressed as 


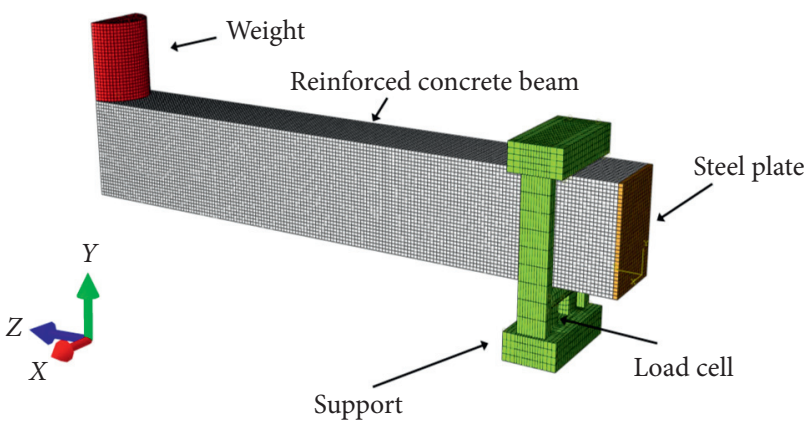

(a)

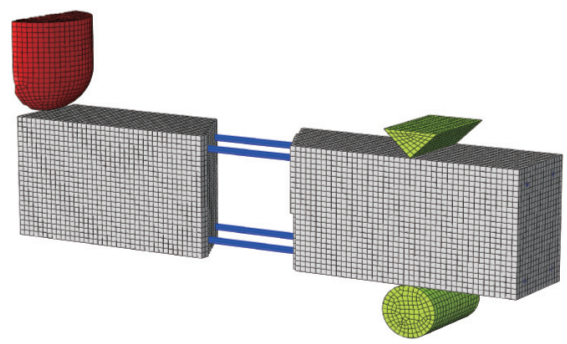

(b)

Figure 5: Numerical model for simply supported beams. (a) For Kishi's tests. (b) For Adhikary et al.'s tests.

TABLE 1: List for geometry parameters of RC beams.

\begin{tabular}{|c|c|c|c|c|c|c|c|c|c|}
\hline \multirow[t]{2}{*}{ No. } & \multirow[t]{2}{*}{$l(\mathrm{~m})$} & \multirow{2}{*}{$\begin{array}{l}\text { Cross section } \\
\qquad(\mathrm{mm})\end{array}$} & \multirow{2}{*}{$\begin{array}{l}\text { Cover thickness } \\
\quad(\mathrm{mm})\end{array}$} & \multicolumn{2}{|c|}{$\begin{array}{l}\text { Main } \\
\text { reinforcing }\end{array}$} & \multirow[t]{2}{*}{$\sigma_{y}(\mathrm{Mpa})$} & \multirow[t]{2}{*}{$N_{0}(\mathrm{~kg})$} & \multirow[t]{2}{*}{$v_{0}(\mathrm{~m} / \mathrm{s})$} & \multirow[t]{2}{*}{$f_{c}^{\prime}(\mathrm{Mpa})$} \\
\hline & & & & $\phi(\mathrm{mm})$ & No. & & & & \\
\hline G3-1 & \multirow{2}{*}{1} & \multirow{2}{*}{$150 \times 250$} & \multirow{2}{*}{40} & \multirow{2}{*}{13} & \multirow{2}{*}{2} & \multirow{2}{*}{393} & \multirow{4}{*}{300} & 4.00 & \\
\hline G3-2 & & & & & & & & 5.00 & 34.6 \\
\hline G4-1 & \multirow[b]{2}{*}{1} & \multirow{2}{*}{$150 \times 250$} & \multirow{2}{*}{40} & \multirow{2}{*}{13} & \multirow{2}{*}{2} & \multirow[b]{2}{*}{373} & & 4.00 & \multirow[b]{2}{*}{32.3} \\
\hline G4-2 & & & & & & & & 5.00 & \\
\hline G5-1 & \multirow{2}{*}{1.5} & \multirow{2}{*}{$200 \times 300$} & \multirow{2}{*}{40} & \multirow{2}{*}{19} & \multirow{2}{*}{2} & \multirow{2}{*}{379} & \multirow{2}{*}{400} & 6.00 & \multirow{2}{*}{39.2} \\
\hline G5-2 & & & & & & & & 7.00 & \\
\hline G6-1 & 1 & $250 \times 250$ & 40 & 19 & 2 & 392 & & 5.00 & 34.7 \\
\hline G10-1 & \multirow{3}{*}{1.5} & \multirow{3}{*}{$200 \times 250$} & \multirow{3}{*}{40} & & & & 300 & 4.00 & \\
\hline G10-2 & & & & 19 & 2 & 404 & 300 & 5.00 & 23.5 \\
\hline G10-3 & & & & & & & & 6.00 & \\
\hline G11-1 & & & & & & & & 3.13 & \\
\hline G11-2 & & & & & & & & 4.20 & \\
\hline G11-3 & & & & & & & & 5.05 & 236 \\
\hline G11-4 & 1.35 & $200 \times 300$ & 50 & 22 & 2 & 401 & 500 & 5.78 & 23.0 \\
\hline G11-5 & & & & & & & & 6.42 & \\
\hline G11-6 & & & & & & & & 7.00 & \\
\hline & & & & & & & & 3.43 & \\
\hline DR3.8_0.8_0.11 & 1 & $160 \times 240$ & 30 & 13 & 2 & 520 & 300 & 4.20 & 40 \\
\hline & & & & & & & & 4.85 & \\
\hline
\end{tabular}

$$
\sigma_{c}=\left(1-d_{c}\right) E_{0}\left(\varepsilon_{c}-\widetilde{\mathcal{\varepsilon}}_{c}^{\mathrm{p}}\right)
$$

in which $\widetilde{\mathcal{E}}_{c}^{\mathrm{pl}}$ represents the equivalent plastic strain for compression. In Abaqus, the relationship between $\widetilde{\mathcal{E}}_{c}^{\mathrm{pl}}$ and $\widetilde{\varepsilon}_{c}^{\text {in }}$ (the inelastic strain) is as follows:

$$
\widetilde{\varepsilon}_{c}^{\mathrm{pl}}=\widetilde{\varepsilon}_{c}^{\mathrm{in}}-\frac{d_{c}}{\left(1-d_{c}\right)} \frac{\sigma_{c}}{E_{0}} .
$$

On the tension side presented in Figure $8(\mathrm{~b})$, the material is linear elastic before reaching $\sigma_{t 0}$ (the failure stress), and microcracks are generated when $\sigma_{t 0}$ is reached. Then, the appearance of microcrack groups softens the macroscopic mechanical properties of the material, which means the stiffness degradation by the path $\left(1-d_{t}\right) E_{0}$. And the stress versus strain relationship for tension is obtained as

$$
\sigma_{t}=\left(1-d_{t}\right) E_{0}\left(\varepsilon_{t}-\widetilde{\varepsilon}_{t}^{\mathrm{pl}}\right)
$$

where $\widetilde{\varepsilon}_{t}^{\mathrm{pl}}$ is the equivalent plastic strain for tension. Moreover, the relationship between $\widetilde{\varepsilon}_{t}^{\mathrm{pl}}$ and $\widetilde{\varepsilon}_{t}^{\mathrm{ck}}$ (the cracking strain) is

$$
\widetilde{\varepsilon}_{t}^{\mathrm{pl}}=\widetilde{\varepsilon}_{t}^{\mathrm{ck}}-\frac{d_{t}}{\left(1-d_{t}\right)} \frac{\sigma_{t}}{E_{0}} .
$$

In actual structural simulation, because of the lack of test data, the specific parameters can be determined by the stressstrain relationship given by the concrete structure design code [34]; besides, damaged factors $d_{c}$ and $d_{t}$ can be determined by the Sidiroff energy equivalence principle. Recently, a lot of research studies focus on the materials' parameter calibration and verification of the CDP model [35-37], and these parameters are used in this study and are shown in Table 2.

Meanwhile, the reinforcements are assumed as elasticplastic material, and the parameters for these models are listed in Table 1. 


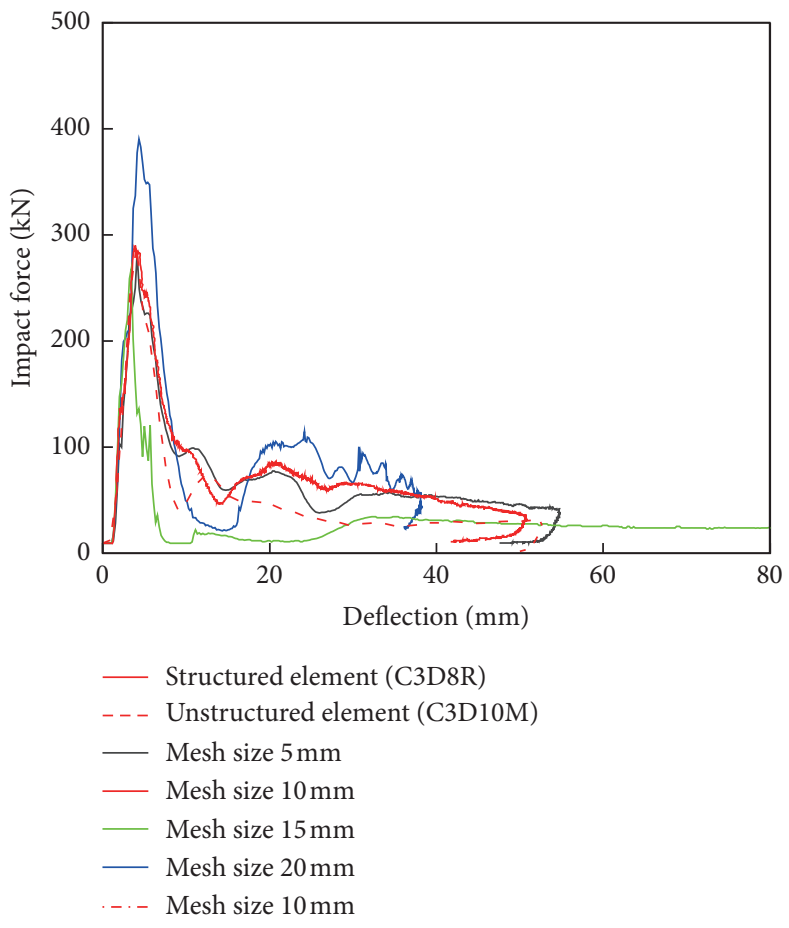

(a)

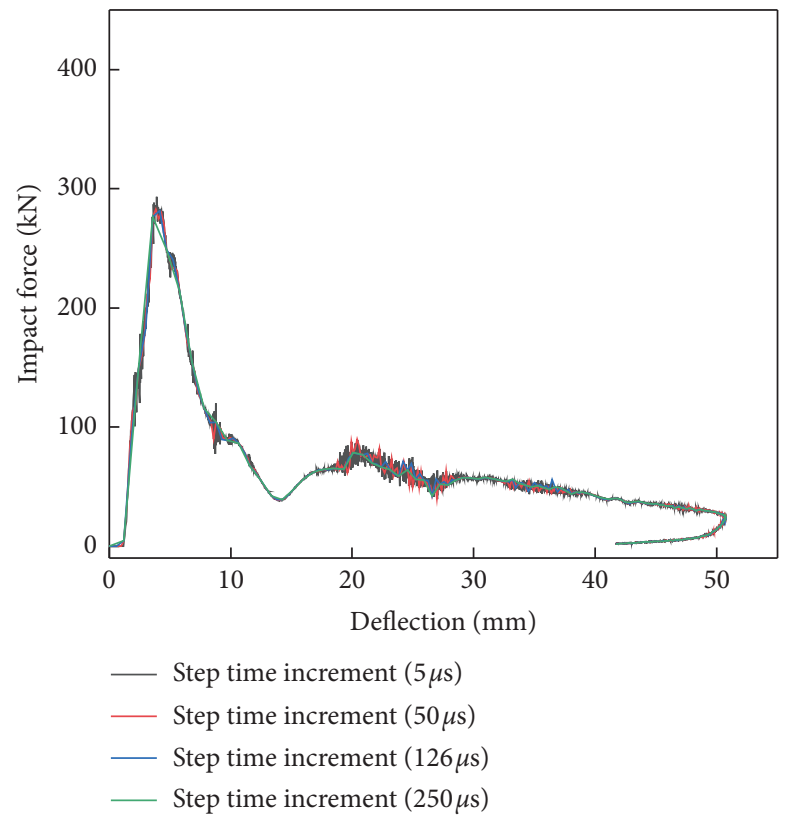

(b)

(c)

Figure 6: Comparison of a typical simulation with different discretizations. (a) The impact force-deflection curves for the RC beam with different mesh sizes. (b) Failure pattern for the structure with different mesh sizes. (c) The impact force-deflection curves for the RC beam with different step time increments.

3.3. Strain Rate Effect. Under high-speed impact or blast loading, the strain rate effects are significant factors to the response of the structures and are considered as natural properties of a material. The strain rate effect was defined as the dynamic increase factor (DIF) with given strain rate. The strength of the steel with high strain rates can higher up to $50 \%$ than in static condition [38, 39]. For concrete with high strain rate, the compressive and tensile strength could be up to $100 \%$ and $600 \%$, respectively. And many DIF relations have been proposed for both steel and concrete materials. However, for the concrete material with low strain rate less than $10 \mathrm{~s}^{-1}$, it 


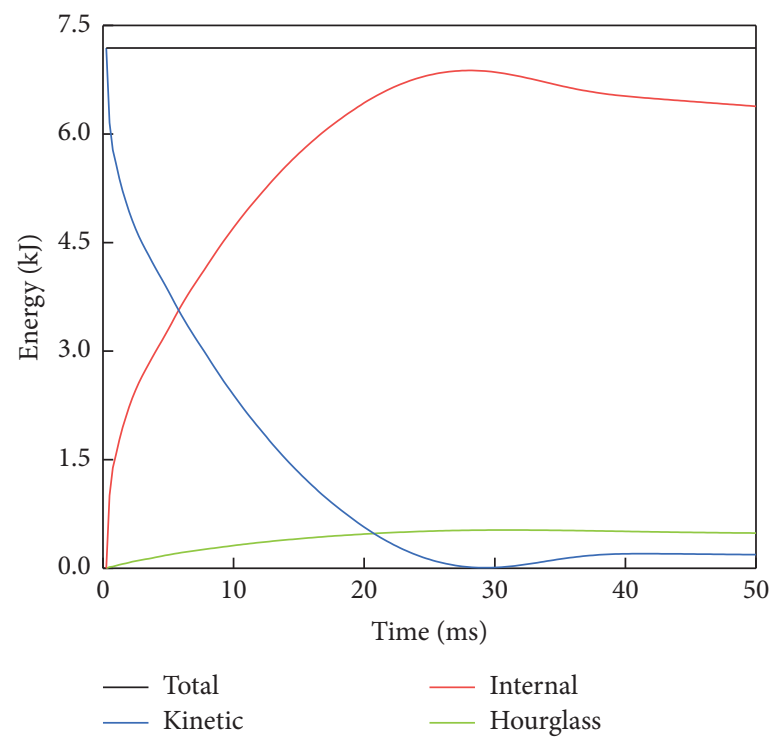

FIGURE 7: Variation of various energies in a typical impact simulation.

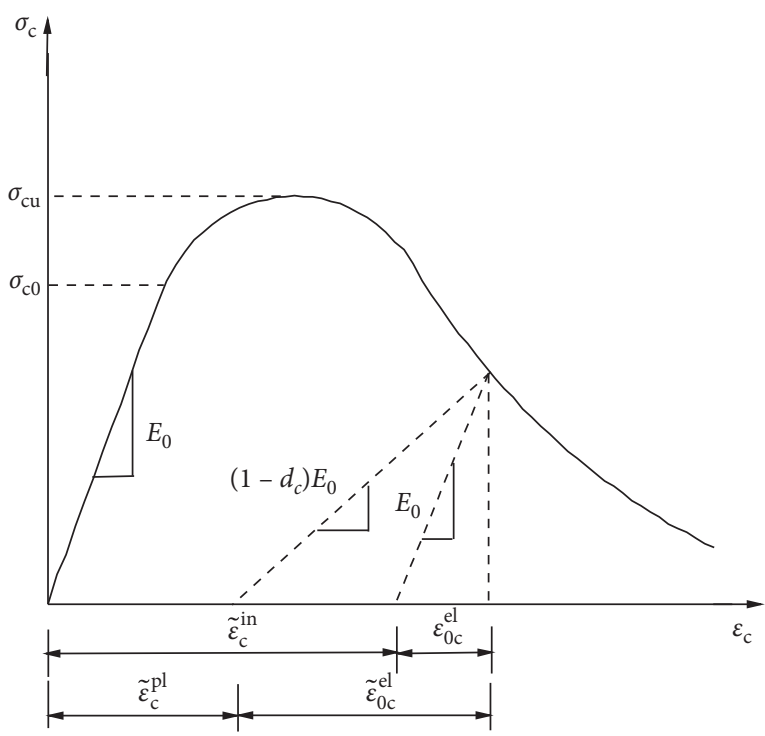

(a)

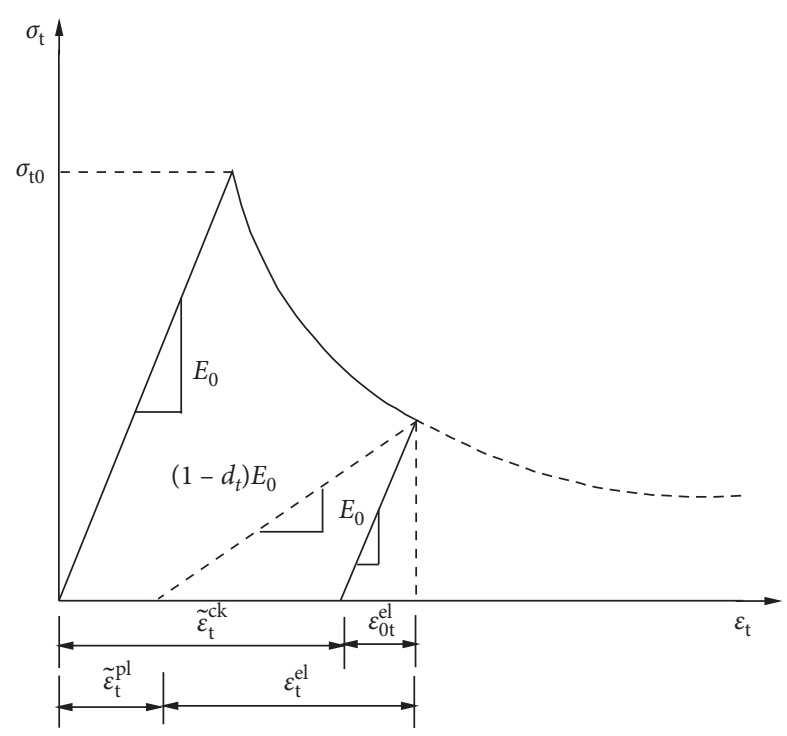

(b)

FIgure 8: Constitutive laws for the CDP model. (a) Compression. (b) Tension.

TABLE 2: Material parameters for the CDP model.

\begin{tabular}{lcccccccc}
\hline Strength grade & $\rho$ (tone $\left./ \mathrm{mm}^{3}\right)$ & $E(\mathrm{Mpa})$ & $v$ & Dilation angle $\left(^{\circ}\right)$ & Eccentricity & $f_{b 0} / f_{c 0}$ & $\mathrm{~K}$ & Viscosity parameter $(\mathrm{E})$ \\
\hline C30 & $2.39 E-09$ & 30000 & 0.2 & 38 & 0.1 & 1.16 & 0.6667 & $1-5$ \\
C40 & $2.40 E-09$ & 32500 & 0.2 & 38 & 0.1 & 1.16 & 0.6667 & $1-5$ \\
C45 & $2.41 E-09$ & 33500 & 0.2 & 38 & 0.1 & 1.16 & 0.6667 & $1-5$ \\
C50 & $2.42 E-09$ & 34500 & 0.2 & 38 & 0.1 & 1.16 & 0.6667 & $1-5$ \\
\hline
\end{tabular}

was considered that the cohesive mechanism is the dominant factor to the strength of the concrete. Only for concrete with strain rate more than $10 \mathrm{~s}^{-1}$, the inertial effect should be taken into account $[40,41]$. Hence, it is reasonable to use the CDP model to simulate the concrete material under low-speed impact. As for steel materials, the strain rate effects are still taken into account in this section, and the DIF for steel is given by [42] 

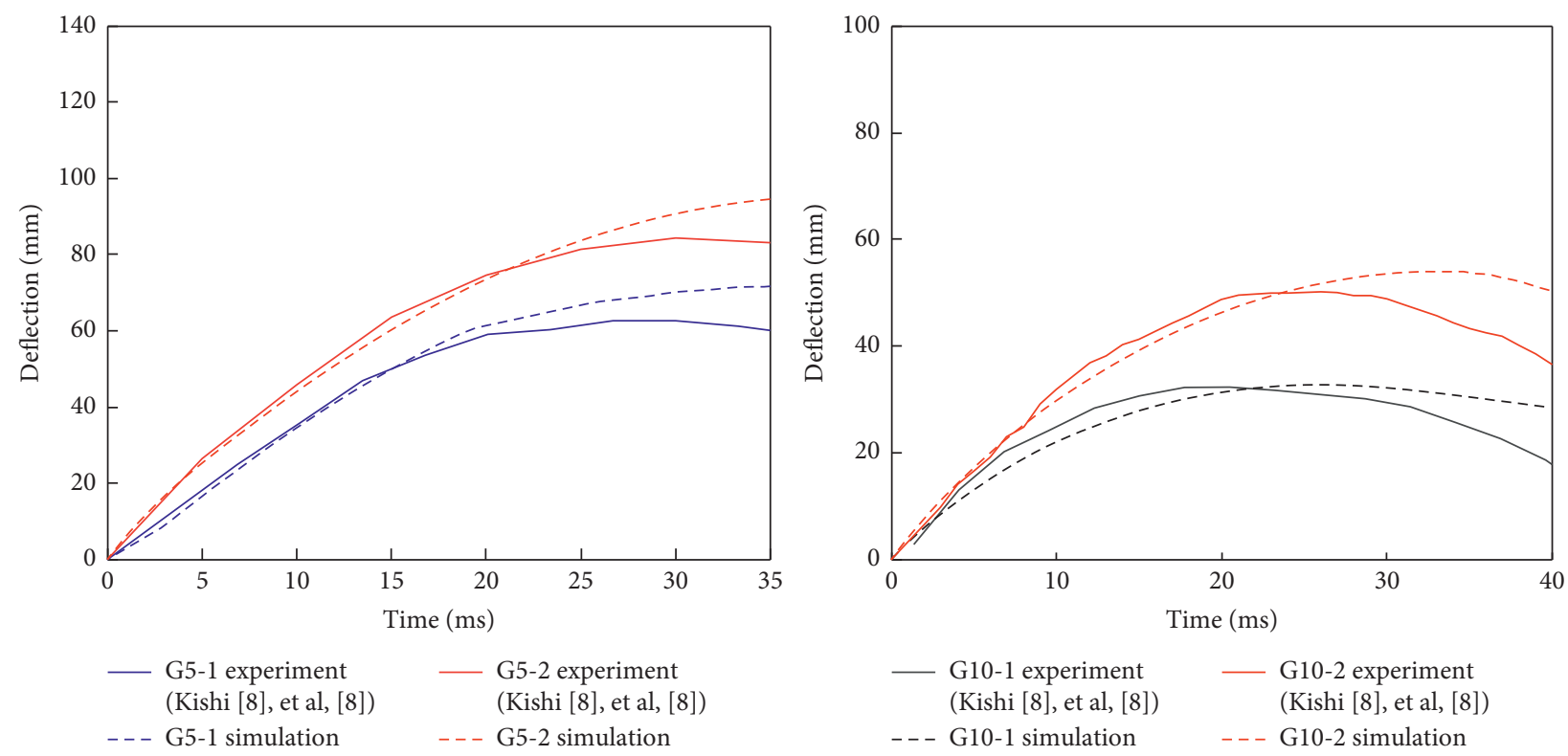

(a)

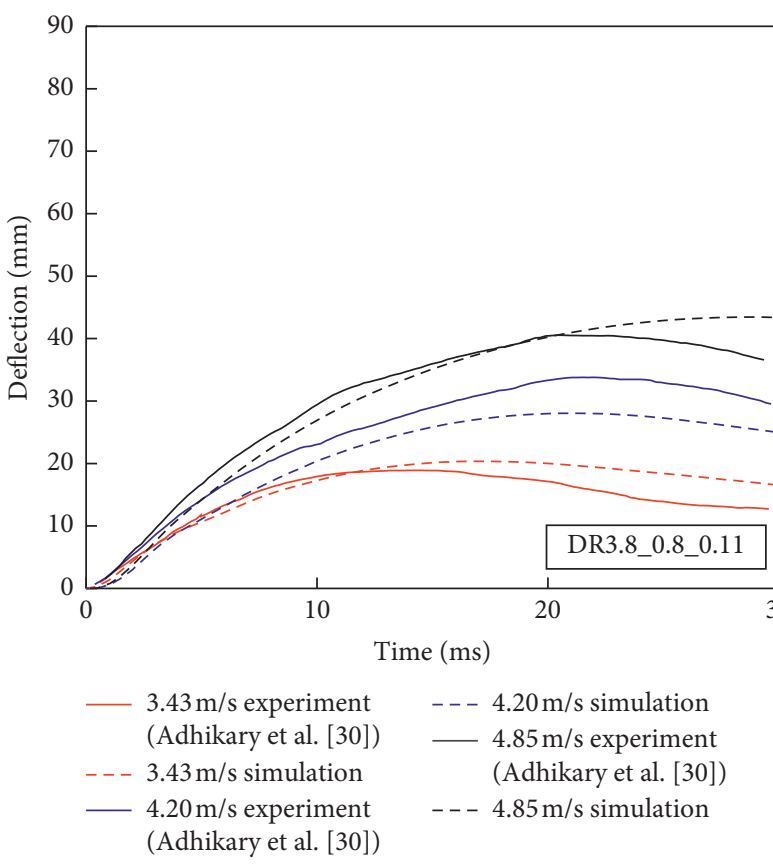

(b)

Figure 9: Comparison of the midspan deflection time histories for RC beams between the simulation and experiments. (a) Kishi's experiments. (b) Adhikary et al.'s experiments.

$$
\begin{aligned}
D I F & =\frac{f_{\mathrm{yd}}}{f_{\mathrm{ys}}} \\
& =1+\frac{6.0}{f_{\mathrm{yt}}} \ln \left(\frac{\dot{\varepsilon}}{\dot{\varepsilon}_{0}}\right), \\
D I F & =\frac{f_{\mathrm{ud}}}{f_{\mathrm{us}}} \\
& =1+\frac{1.5}{f_{\mathrm{ut}}} \ln \left(\frac{\dot{\varepsilon}}{\dot{\varepsilon}_{0}}\right),
\end{aligned}
$$

where $\dot{\varepsilon}_{0}=0.00005 \mathrm{~s}^{-1}, f_{\mathrm{ys}}$ and $f_{\mathrm{yd}}$ represent the yield strength for steel under static and dynamic loading, respectively, and $f_{\text {us }}$ and $f_{\text {ud }}$ are the ultimate strength for steel under static and dynamic conditions, respectively.

\section{Results and Discussion}

4.1. Numerical Investigation Verification. Finite element analyses are carried out to simulate the response of the tests listed above. As some tested series have not presented the important information about the impact force time history, 


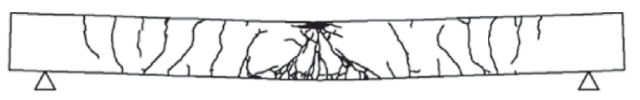

$\mathrm{G} 5-1(V=6 \mathrm{~m} / \mathrm{s})$

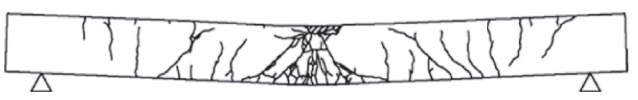

$\mathrm{G} 5-2(V=7 \mathrm{~m} / \mathrm{s})$
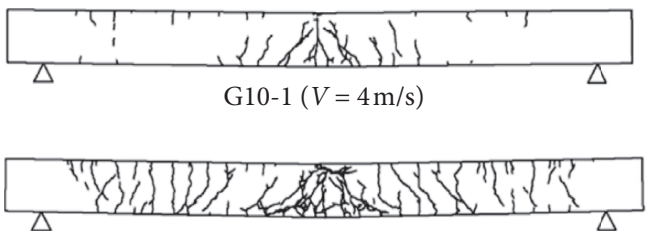

G10-2 $(V=5 \mathrm{~m} / \mathrm{s})$

$3.43 \mathrm{~m} / \mathrm{s}$

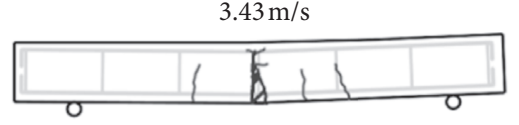

$4.20 \mathrm{~m} / \mathrm{s}$

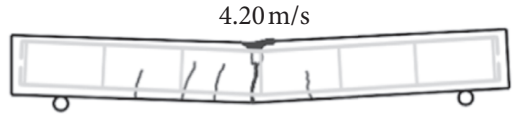

$4.85 \mathrm{~m} / \mathrm{s}$

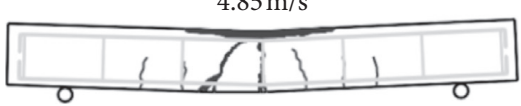

DR3.8 $0.8 \quad 0.11$

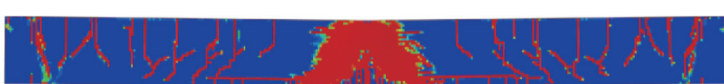

G5-1

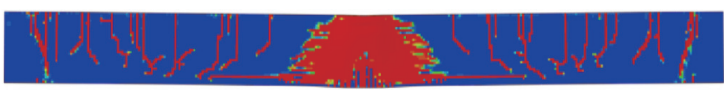

G5-2

(a)

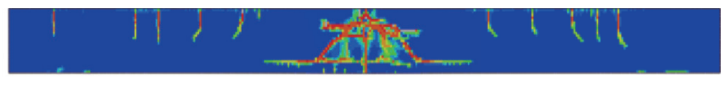

G10-1

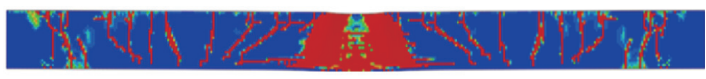

G10-2

(b)

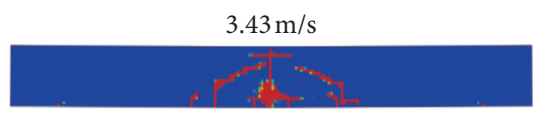

$4.20 \mathrm{~m} / \mathrm{s}$
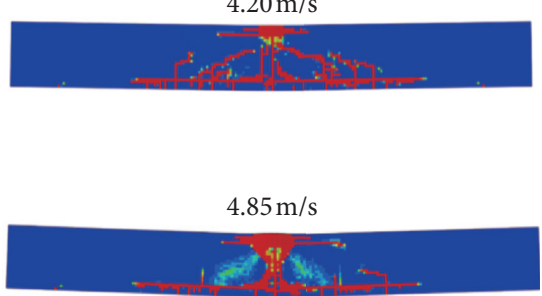

DR3.8 $0.8 \quad 0.11$

(c)

FIGURE 10: Comparison of the damage pattern for RC beams between the simulation and experiments. (a) Kishi's experiment series G5. (b) Kishi's experiment series G10. (c) Adhikary et al.'s experiments.

only series G5 and G10 in Kishi's experiments are compared for this parameter. Moreover, the comparison between the simulations and experiments for both the midspan time history and the damage pattern for series G5 and G10 carried out by Kishi and series DR3.8_0.8_0.11 conducted by Adhikary et al. [30] is shown in Figures 9 and 10. And the impact force time history for series G5 and G10 are presented in Figure 11, and the values of thepeak impact load are efficient for both four cases compared with the experiment data. . Figure 9(a) shows that the maximum deflection for beam G5-1 in simulation and tests is $71.34 \mathrm{~mm}$ and $63.5 \mathrm{~mm}$, respectively, with 83.42 and $71.57 \mathrm{~mm}$ for beam G5-2. As for series G10 and DR3.8_0.8_0.11, smaller errors are presented. More data about the peak impact force and the maximum deflection for $19 \mathrm{RC}$ beams in different conditions with different impact velocities or parameters are compared and listed in Table 3, which indicated that the simulation results agree well with the experiments. Figure 10 presents the tension damage contour plots for beams in Abaqus; it can be seen that the crack profiles in simulation are almost consistent with the experiment one. In summary, the simulations carried out in this study can reproduce the test results with high accuracy. On the contrary, the material parameters for the CDP model mentioned in the previous section are verified to be reliable.

Furthermore, beams with the same parameters in fully clamped condition are modeled, and the maximum displacements in simulations are also displayed in Table 3. From the comparison between the simply supported and fully clamped beams, it follows that the boundary condition has more significant influence on the deflection response of the beams which is "relatively long." For example, the average ratio for the maximum deflection of G10 beams with full span $3 \mathrm{~m}$ in the fully clamped case to simply supported condition is 0.39 , compared to the G3 beams with full span $2 \mathrm{~m}$ of 0.60 , which is due to that stationary points for "relatively long" RC beams cannot reach the boundary when the peak impact force is reached [16].

4.2. Theoretical Model Verification. It has been mentioned in the Introduction section that investigations have been 

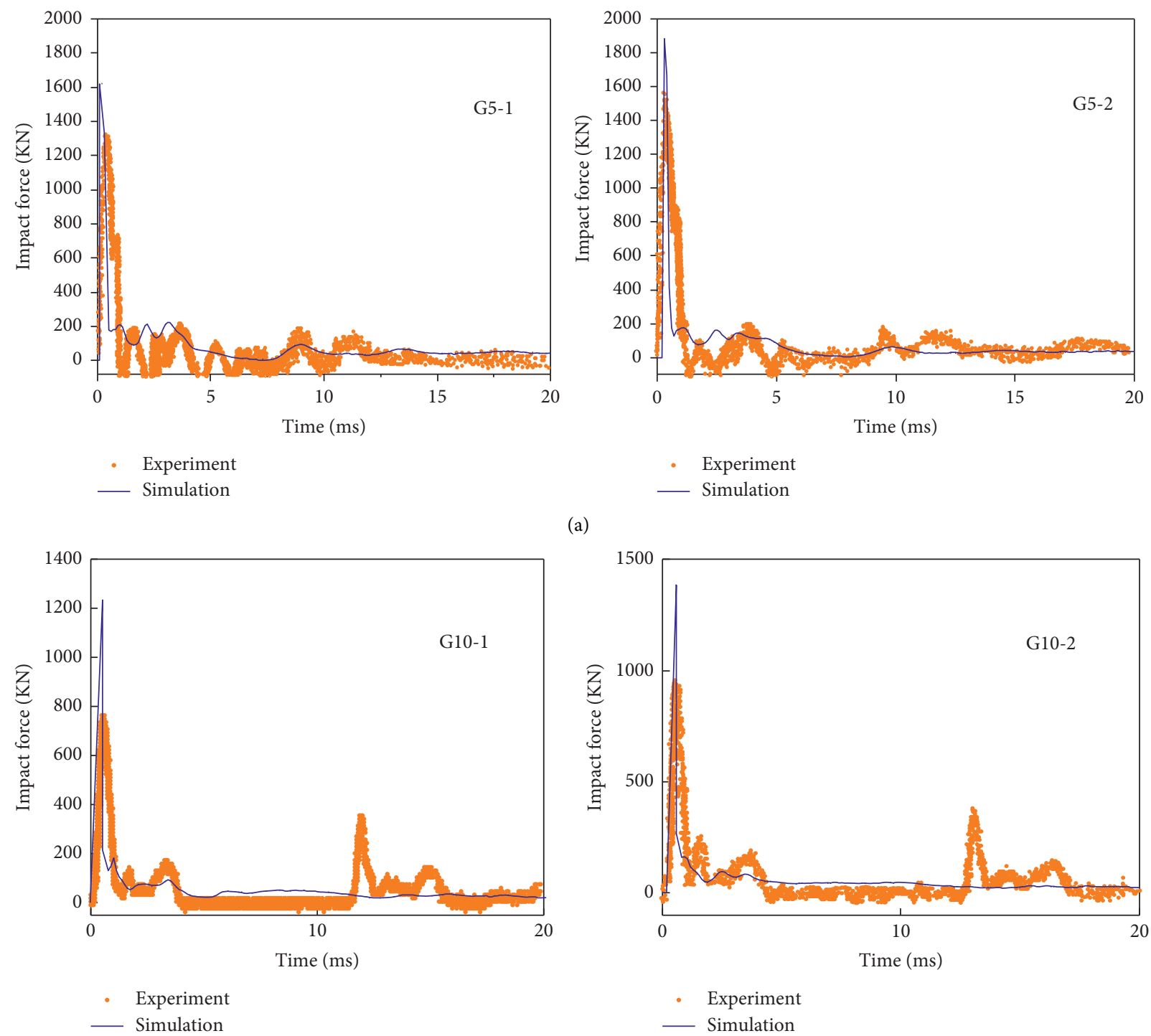

(a)

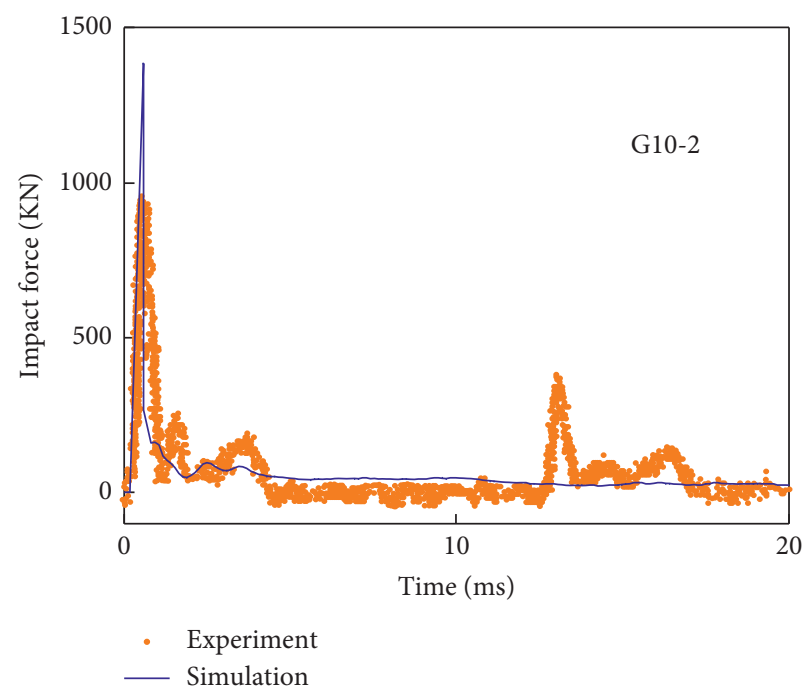

(b)

Figure 11: Comparison of the impact force time histories for RC beams between the simulation and Kishi's experiments. (a) Series G5. (b) Series G10.

proposed verifying that, for relatively low loading rate, the failure of the RC beams is mainly due to bending, and with increase in loading rate, there is a transition of the failure mode from bending to shear. So, it is relatively rational to calculate the deflection response of the RC beams neglecting the effect of the shear. The verification for both these theoretical models is as follows.

4.2.1. Simply Supported RC Beams. As mentioned in Section 2 , the same expression for the maximum deflection response of the double reinforcement beams is given by two methods, see (17). To validate the proposed prediction, theoretical predictions for $83 \mathrm{RC}$ beams tested under low-speed impact are obtained by (17), and the comparison with the experimental results [7, 8, 30, 43-47] is shown in Figure 12.

It is observed that values of the theoretical model reasonably agree with the experiment results, except which are shown in blue. The correlation factor of the experiment results and theoretical predictions is $R^{2}=0.978$, and the average error is given by $12.5 \%$. As for the cases with bigger error in blue which are named by G2 [8], G2 and G4 are basically the same except that the compressive strength is $0.1 \mathrm{Mpa}$ which is slightly different. Moreover, the comparison for G4 series beams is shown in detail (see Figure 13(a)), and the theoretical prediction is in good agreement with the experimental results. It is reasonable to think that the larger error for G2 series is roughly attributed to the relative randomness of the experiments in this paper. Furthermore, the relationship between the input energy and the maximum deflection of beams is presented (see Figure 13), and the maximum deflections of these beams are linearly proportional to the input impact energy, which is consistent with the theoretical model.

It is also shown that most of the theoretical results somewhat overestimate the maximum deflection of the 
TABLE 3: List of simulation results.

\begin{tabular}{|c|c|c|c|c|c|c|}
\hline \multirow[b]{2}{*}{ No. } & \multirow[b]{2}{*}{$v_{0}(\mathrm{~m} / \mathrm{s})$} & \multicolumn{4}{|c|}{ Simply supported beams } & \multirow{2}{*}{$\begin{array}{l}\text { Fully clamped beams } \\
w_{0 f}(\mathrm{~mm}), \text { FEM }\end{array}$} \\
\hline & & $w_{0 f}(\mathrm{~mm})$, experiment & $w_{0 f}(\mathrm{~mm}), \mathrm{FEM}$ & $\begin{array}{l}\text { Max. impact force }(\mathrm{KN}) \text {, } \\
\text { experiment }\end{array}$ & $\begin{array}{c}\text { Max. impact } \\
\text { force }(\mathrm{KN}), \text { FEM }\end{array}$ & \\
\hline G3-1 & 4.00 & 36.7 & 34.58 & 1208.5 & 1152.00 & 20.46 \\
\hline G3-2 & 5.00 & 52.0 & 55.33 & 1469.5 & 1118.97 & 33.78 \\
\hline G4-1 & 4.00 & 39.7 & 39.41 & 800.3 & 810.90 & 21.35 \\
\hline G4-2 & 5.00 & 56.1 & 63.17 & 985.8 & 1037.14 & 35.20 \\
\hline G5-1 & 6.00 & 63.5 & 71.74 & 1313.2 & 1620.52 & 34.6 \\
\hline G5-2 & 7.00 & 83.4 & 95.48 & 1557.1 & 1887.29 & 45.49 \\
\hline G6-1 & 5.00 & 26.4 & 29.00 & 1335.9 & 1810.42 & 16.58 \\
\hline G10-1 & 4.00 & 33.7 & 34.40 & 750.7 & 1042.50 & 12.83 \\
\hline G10-2 & 5.00 & 49.5 & 56.61 & 922.3 & 1136.40 & 19.51 \\
\hline G10-3 & 6.00 & 67.8 & 78.71 & 1016.9 & 1633.50 & 27.52 \\
\hline G11-1 & 3.13 & 20.5 & 21.01 & 702.8 & 761.57 & 11.41 \\
\hline G11-2 & 4.20 & 33.2 & 36.85 & 971.0 & 1268.22 & 19.10 \\
\hline G11-3 & 5.05 & 43.1 & 51.12 & 1461.5 & 1560.00 & 25.97 \\
\hline G11-4 & 5.78 & 55.5 & 67.51 & 1877.8 & 1374.36 & 31.99 \\
\hline G11-5 & 6.42 & 67.2 & 80.09 & 1764.8 & 2133.16 & 37.52 \\
\hline G11-6 & 7.00 & 83.4 & 93.54 & 1906.6 & 2717.15 & 42.13 \\
\hline DR3.8_0.8_0.11 & 3.43 & 18.6 & 20.36 & 258.73 & 213.03 & 8.24 \\
\hline DR3.8_0.8_0.11 & 4.20 & 34.5 & 33.77 & 303.03 & 236.12 & 11.70 \\
\hline DR3.8_0.8_0.11 & 4.85 & 41.0 & 43.44 & 348.12 & 260.50 & 15.20 \\
\hline
\end{tabular}

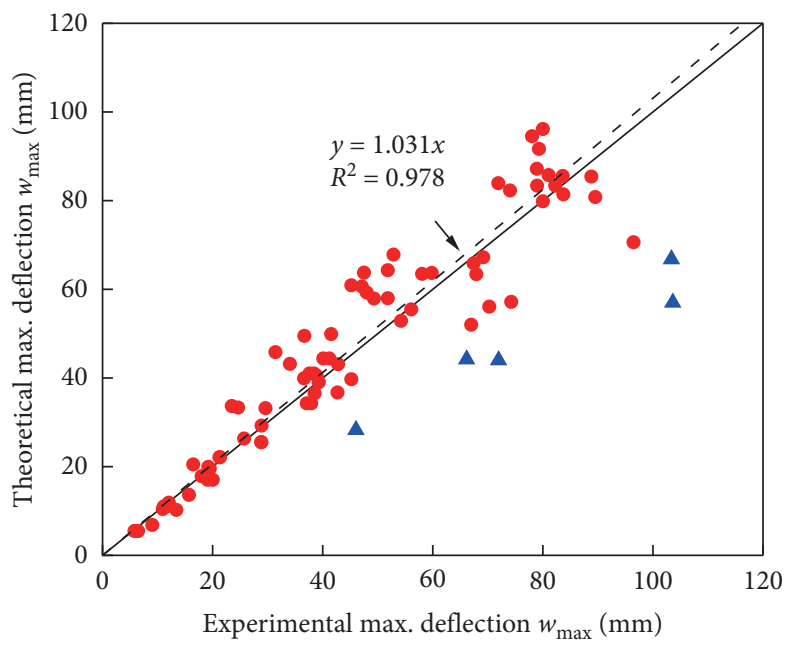

Figure 12: Comparison between the theoretical results and Kishi's experiments for all series of simply supported RC beams. (a) Input energy-deflection curve for test series G3, G4, and G6. (b) Input energy-deflection curve for series G5 and G11.

beams, which is due to the use of the upper-bound theory and neglecting ] the damage for concrete material. Figure 12 presents that the error of the theoretical models increases with the increase of the impact velocity for a specific structure, generally with a larger maximum deflection. In another way, the error of the proposed formula increases when the data are out of the specific range. It confirms that these proposed simplified models have some limitations to predict the maximum deflection of RC beams under impact loading.

4.2.2. Fully Clamped RC Beams. The simulation results for beams with fully clamped condition have been shown in
Table 3. The comparison between the theoretical and simulation results is demonstrated in Figures 14(a) and 15.

It is observed that theoretical results predicted by both extended Hamilton's principle and upper bound method present great agreement with the simulation results. With the use of extended Hamilton's principle, the average error is summarized as $11.13 \%$. For the equivalent static hypothesis, average error is given by $11.17 \%$. From Figures 14 and 15, it can be observed that the correlation factors of the simulations and predictions are $R^{2}=0.985$ and $R^{2}=0.984$ for these two methods, respectively, which indicate that using the equivalent static hypothesis and extended Hamilton's principle can obtain almost the same solutions. And the 


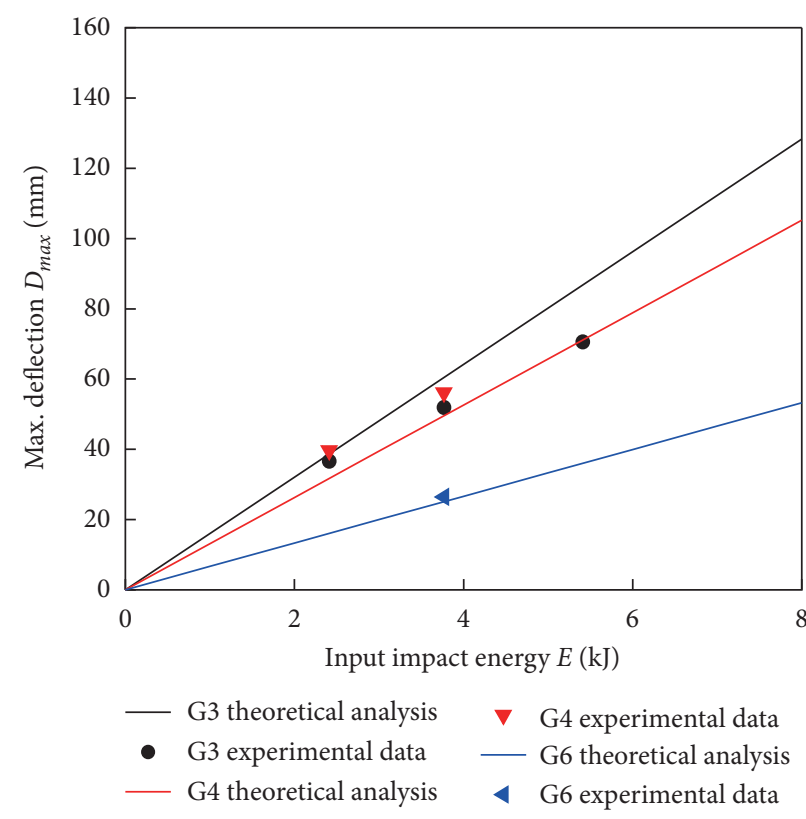

(a)

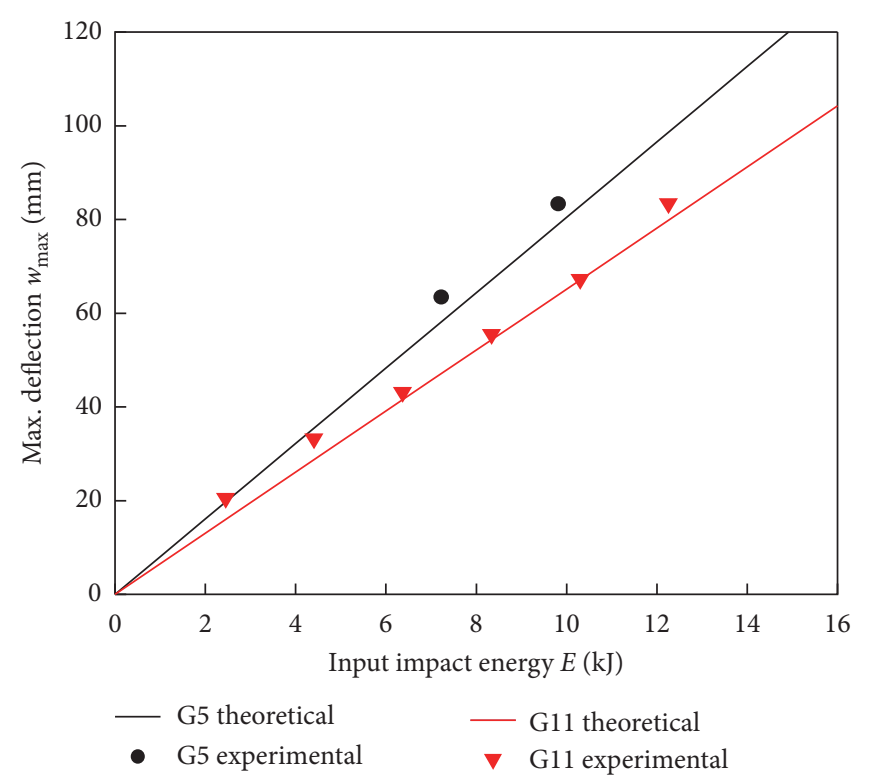

(b)

Figure 13: Comparison between the theoretical results and Kishi's experiments for simply supported RC beams in detail. (a) Series G3, G4, and G6. (b) Series G5 and G11.

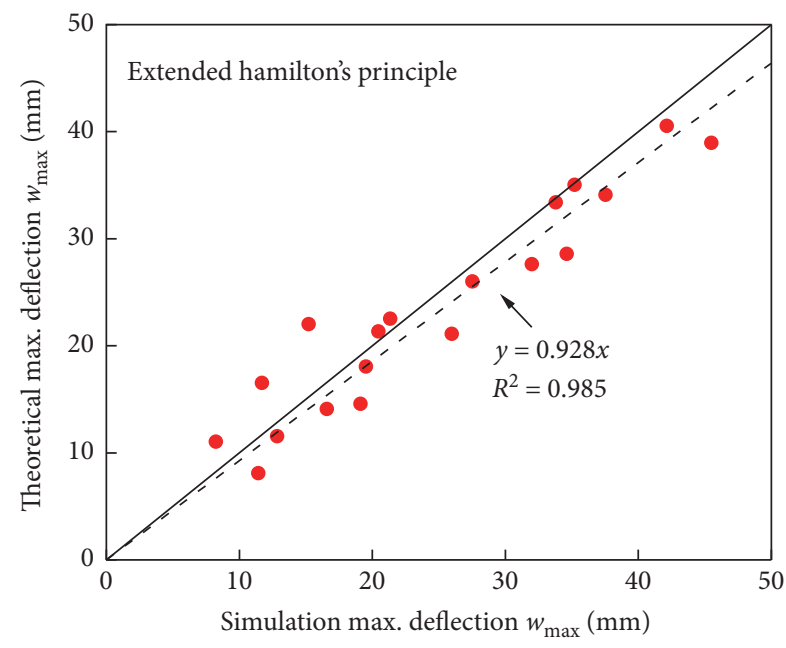

Figure 14: Comparison between the simulation and theoretical results calculated by extended Hamilton's principle for fully clamped RC beams.

maximum midspan deflection-input impact energy relationship given by the equivalent static hypothesis is weak nonlinearity. On the contrary, as the difference for accuracy between these two methods is so small, it is proper to take that the maximum deflections are almost proportional with respect to the input impact energy for fully clamped RC beams.

In conclusion, simpler analytical solutions can be given by extended Hamilton's principle, while the theoretical basis is easier for the equivalent static hypothesis. And "equal

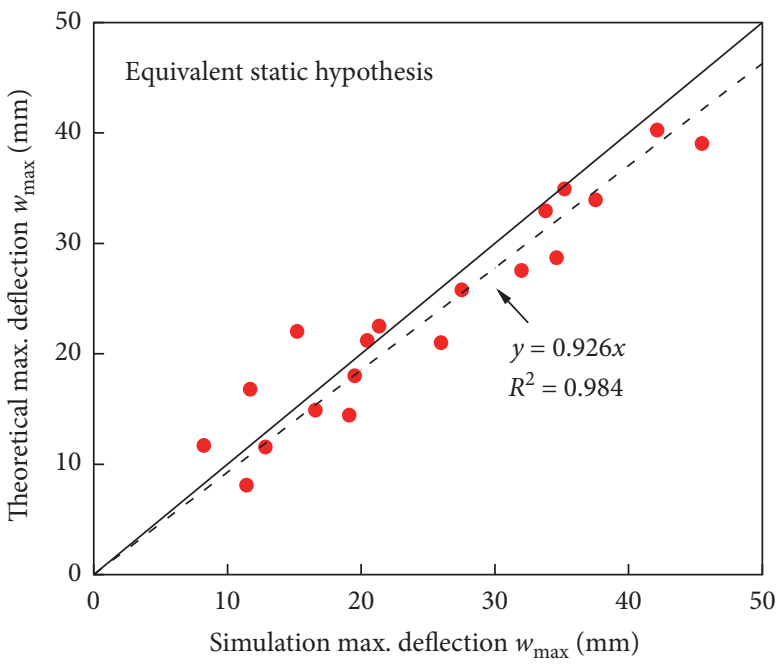

Figure 15: Comparison between the simulation and theoretical results calculated by the equivalent static hypothesis for fully clamped RC beams.

area" hypothesis is used for these two theoretical models, which verified to be a simple tool for the approximate analysis of large deflection of RC beams.

\section{Conclusion}

The dynamic large deflection response for both simply supported and fully clamped RC beams under low-speed impact loading is solved theoretically by both extended Hamilton's principle and equivalent static hypothesis; "equal 
area" method is used in both derivations to determine the plastic limit bending moment of the structure. Finite element analyses are carried out to simulate other impact tests. The main findings are summarized as follows:

(1) Two simple methods are proposed to predicting the maximum deflection-input impact energy relationship for RC beams subjected to low-speed impact loading; these theoretical predictions agree well with both experimental and simulation results. The "equal area" method is suitable for the large deflection analysis of the RC beams.

(2) For simply supported RC beams, the same analytical solution is obtained by both methods. The linear relationship between the input impact energy and the maximum deflection of the RC beams is obtained by equation (17).

(3) For fully clamped RC beams, the linear and nonlinear maximum midspan deflection-input impact energy relationships are given by these two methods. The difference for the accuracy between these two methods is so small; it is proper to take that the maximum deflections are almost proportional with respect to the input impact energy for fully clamped RC beams.

(4) The boundary condition has more effect on the deflection response of the RC beams which is relatively longer.

\section{Data Availability}

The data used to support the findings of this study are available from the corresponding author upon request.

\section{Conflicts of Interest}

The authors declare that there are no conflicts of interest regarding the publication of this paper.

\section{Acknowledgments}

This work was supported by the National Natural Science Foundation of China (Grant no. 11772216), the "1331 Project" Fund and Key Innovation Teams of Shanxi Province and the Top Young Academic Leaders of Shanxi, the Sanjin Young Scholars Project of Shanxi Province, the Youth Academic Backbone Cultivation Project from Taiyuan University of Technology, and the Opening Foundation for State Key Laboratory for Strength and Vibration of Mechanical Structures. The financial contributions are greatly acknowledged.

\section{References}

[1] British Standards Institution, National Annex to Eurocode 1: Actions on Structures-Part 2: Traffic Loads on Bridges, NA to BS EN 1991-2: 2003, British Standards Institution, London, UK, 2008.
[2] L. Aashto, Bridge Design Specifications, American association of state highway and transportation officials, Washington, DC, USA, 2012.

[3] T. M. Pham and H. Hao, "Plastic hinges and inertia forces in RC beams under impact loads," International Journal of Impact Engineering, vol. 103, pp. 1-11, 2017.

[4] K. N. Ando T, H. Mikami, M. Sato, and K. G. Matsuoka, "Experimental study on impact resistance of bending failure type of RC beams," Doboku Gakkai Ronbunshu, vol. 647, pp. 1075-1080, 1999.

[5] N. Kishi, H. Mikami, and T. AndoMatsuoka, "An empirical impact resistant design formula of RC beams with statically bending failure mode," Doboku Gakkai Ronbunshu, vol. 647, no. 647 , pp. 177-190, 2000.

[6] C. Y. May IM, D. R. J. Owen, Y. T. Feng, and A. T. Bere, "Experimental testing and finite element simulation of the behavior of reinforced concrete beams under impact loading," in Proceedings of the VIII International Conference on Computational Plasticity, Barcelona, Spain, 2005.

[7] S. Tachibana, H. Masuya, and S. Nakamura, "Performance based design of reinforced concrete beams under impact," Natural Hazards and Earth System Sciences, vol. 10, no. 6, pp. 1069-1078, 2010.

[8] M. H. Kishi, "Empirical formulas for designing reinforced concrete beams under impact loading," ACI Structural Journal, vol. 109, no. 4, pp. 509-519, 2012.

[9] D. M. Cotsovos, "A simplified approach for assessing the loadcarrying capacity of reinforced concrete beams under concentrated load applied at high rates," International Journal of Impact Engineering, vol. 37, no. 8, pp. 907-917, 2010.

[10] T. Zhan, Z. Wang, and J. Ning, "Failure behaviors of reinforced concrete beams subjected to high impact loading," Engineering Failure Analysis, vol. 56, 2015.

[11] T. M. Pham and H. Hao, "Review of concrete structures strengthened with FRP against impact loading," Structures, vol. 7, pp. 59-70, 2016.

[12] H. Jiang and S. He, "Numerical simulation of impact tests on reinforced concrete beams," Materials \& Design, vol. 39, 2012.

[13] J. Hua and G. C. Mi, "An effective numerical simulation methodology to predict the impact response of pre-stressed concrete members," Engineering Failure Analysis, vol. 55, pp. 63-78, 2015.

[14] H. M. I. Thilakarathna, D. P. Thambiratnam, M. Dhanasekar, and N. Perera, "Numerical simulation of axially loaded concrete columns under transverse impact and vulnerability assessment," International Journal of Impact Engineering, vol. 37, no. 11, pp. 1100-1112, 2010.

[15] R. Villavicencio and C. Guedes Soares, "Numerical modelling of the boundary conditions on beams stuck transversely by a mass," International Journal of Impact Engineering, vol. 38, no. 5, pp. 384-396, 2011.

[16] T. M. Pham and H. Hao, "Effect of the plastic hinge and boundary conditions on the impact behavior of reinforced concrete beams," International Journal of Impact Engineering, vol. 102, no. 1, pp. 74-85, 2017.

[17] W. Chen, H. Hao, and S. Chen, "Numerical analysis of prestressed reinforced concrete beam subjected to blast loading," Materials \& Design (1980-2015), vol. 65, pp. 662-674, 2015.

[18] V. Travaš, J. Ožbolt, and I. Kožar, "Failure of plain concrete beam at impact load: 3D finite element analysis," International Journal of Fracture, vol. 160, no. 1, pp. 31-41, 2009.

[19] T. Rabczuk and T. Belytschko, "A three-dimensional large deformation meshfree method for arbitrary evolving cracks," 
Computer Methods in Applied Mechanics and Engineering, vol. 196, no. 29-30, pp. 2777-2799, 2007.

[20] T. Rabczuk and T. Belytschko, "Cracking particles: a simplified meshfree method for arbitrary evolving cracks," International Journal for Numerical Methods in Engineering, vol. 61, no. 13, pp. 2316-2343, 2004.

[21] M. Szczecina and A. Winnicki, "Selected aspects of computer modeling of reinforced concrete structures," Archives of Civil Engineering, vol. 62, no. 1, pp. 51-64, 2016.

[22] M. S. A. Winnicki, "Relaxation time in CDP model used for analyses of RC structures," Procedia Engineering, vol. 193, pp. 369-376, 2017.

[23] Y. Su, J. Li, C. Wu, P. Wu, and Z.-X. Li, "Influences of nanoparticles on dynamic strength of ultra-high performance concrete," Composites Part B: Engineering, vol. 91, pp. 595609, 2016.

[24] P. A. Buchan and J. F. Chen, "Blast resistance of FRP composites and polymer strengthened concrete and masonry structures-a state-of-the-art review," Composites Part B: Engineering, vol. 38, no. 5-6, pp. 509-522, 2007.

[25] M. N. S. Hadi, T. M. Pham, and X. Lei, "New method of strengthening reinforced concrete square columns by circularizing and wrapping with fiber-reinforced polymer or steel straps," Journal of Composites for Construction, vol. 17, no. 2, pp. 229-238, 2013.

[26] X. Lei, Design Guidance for Strengthening Concrete Structures Using Fibre Composite Material, Concrete Society, Camberley, UK, 2012.

[27] W. Alnahhal and O. Aljidda, "Flexural behavior of basalt fiber reinforced concrete beams with recycled concrete coarse aggregates," International Journal of Solids and Structures, vol. 169, pp. 165-178, 2018.

[28] M. Taya and T. Mura, "Dynamic plastic behavior of structures under impact loading investigated by the extended Hamilton's principle," International Journal of Solids and Structures, vol. 10, no. 2, pp. 197-209, 1974.

[29] C. R. Calladine, Simple Ideas in the Large-Deflection Plastic Theory of Plates and Slabs, Cambridge University Press, Cambrige, UK, 1968.

[30] S. D. Adhikary, B. Li, and K. Fujikake, "Low velocity impact response of reinforced concrete beams: experimental and numerical investigation," International Journal of Protective Structures, vol. 6, no. 1, pp. 81-111, 2015.

[31] S. V. Chaudhari and M. A. Chakrabarti, "Modeling of concrete for nonlinear analysis using finite element code ABAQUS," International Journal of Computer Applications, vol. 44, no. 7, pp. 14-18, 2012.

[32] J. Lubliner, J. Oliver, S. Oller, and E. Oñate, "A plastic-damage model for concrete," International Journal of Solids and Structures, vol. 25, no. 3, pp. 299-326, 1989.

[33] J. Lee and G. L. Fenves, "Plastic-damage model for cyclic loading of concrete structures," Journal of Engineering $\mathrm{Me}$ chanics, vol. 124, no. 8, pp. 892-900, 1998.

[34] Ministry of Construction of the People's Republic of China, Code for Design of Concrete Structures : GB 50010-2002, China Architecture \& Building Press, Cambrige, UK, 2002.

[35] L. Wei, X. Ming, and C. Zhongfan, "Parameters calibration and verification of concrete damage plasticity model of ABAQUS," Industrial Construction, vol. 44, pp. 167-213, 2014, in Chinese.

[36] X. Jingang, D. Li, and T. Qin, "Parameter calculation method and experimental verification for concrete damage plastic model," Journal of Nanchang University(Engineering \& Technology), vol. 41, no. 1, pp. 21-26, 2019, in Chinese.
[37] J. Zhang, Q. Wang, and S. Hu, "Parameters verification of concrete damaged plastic model of ABAQUS," Building Structure, vol. 38, no. 8, pp. 127-130, 2008, in Chinese.

[38] Y. Hao and H. Hao, "Influence of the concrete DIF model on the numerical predictions of $\mathrm{RC}$ wall responses to blast loadings," Engineering Structures, vol. 73, pp. 24-38, 2014.

[39] L. J. Malvar, "Review of static and dynamic properties of steel reinforcing bars," Aci Materials Journal, vol. 95, no. 5, pp. 609-616, 1998.

[40] P. Rossi and F. Toutlemonde, "Effect of loading rate on the tensile behaviour of concrete: description of the physical mechanisms," Materials and Structures, vol. 29, no. 2, pp. 116-118, 1996.

[41] M. E. Kipp, D. E. Grady, and E. P. Chen, "Strain-rate dependent fracture initiation," International Journal of Fracture, vol. 16, no. 5, pp. 471-478, 1980.

[42] E. J, "Concrete structures under impact and impulsive loading," Dubrovnik:Comite Euro-International du Beton, vol. $16,1988$.

[43] G. Q. Dou, X. . 1. Du, and L. Li, "Experimental study on thebehavior of high strength reinforced concrete beams under impact load," Journal of Tianjin University (Science and Technology), vol. 16, no. 47, pp. 1072-1080, 2014, in Chinese.

[44] D. B. Zhao and W. J. Yi, "Anti-impact behavior and design method for RC beams," Zhendong Yu Chongji/Journal of Vibration and Shock, vol. 34, no. 11, pp. 139-145, 2015, in Chinese.

[45] A. Q. Bhatti, N. Kishi, H. Mikami, and T. Ando, "Elastoplastic impact response analysis of shear-failure-type RC beams with shear rebars," Materials \& Design, vol. 30, no. 3, pp. 502-510, 2009.

[46] K. Fujikake, B. Li, and S. Soeun, "Impact response of reinforced concrete beam and its analytical evaluation," Journal of Structural Engineering, vol. 135, no. 8, pp. 938-950, 2009.

[47] D. B. Zhao, W. J. Yi, and S. K. Kunnath, "Shear mechanisms in reinforced concrete beams under impact loading," Journal of Structural Engineering, vol. 143, no. 9, pp. 1-13, 2017. 